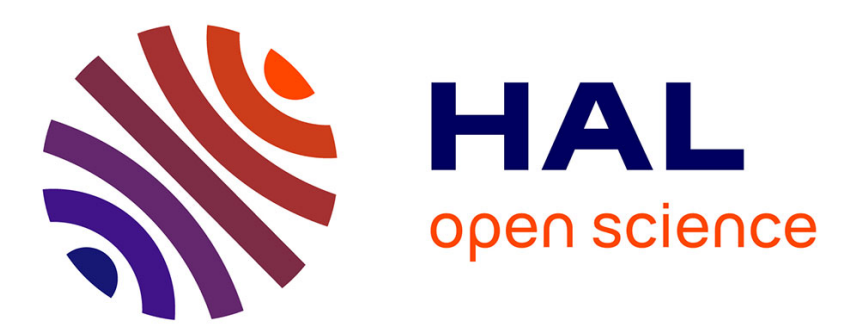

\title{
DABCO-promoted Diaryl Thioether Formation by Metal-catalyzed Coupling of Sodium Sulfinates and Aryl Iodides
}

Yanpeng Liu, Long Yin Lam, Jiqing Ye, Nicolas Blanchard, Cong Ma

\section{- To cite this version:}

Yanpeng Liu, Long Yin Lam, Jiqing Ye, Nicolas Blanchard, Cong Ma. DABCO-promoted Diaryl Thioether Formation by Metal-catalyzed Coupling of Sodium Sulfinates and Aryl Iodides. Advanced Synthesis and Catalysis, 2020, 362 (12), pp.2326-2331. 10.1002/adsc.202000221 . hal-02991822

\section{HAL Id: hal-02991822 \\ https://hal.science/hal-02991822}

Submitted on 12 Nov 2020

HAL is a multi-disciplinary open access archive for the deposit and dissemination of scientific research documents, whether they are published or not. The documents may come from teaching and research institutions in France or abroad, or from public or private research centers.
L'archive ouverte pluridisciplinaire HAL, est destinée au dépôt et à la diffusion de documents scientifiques de niveau recherche, publiés ou non, émanant des établissements d'enseignement et de recherche français ou étrangers, des laboratoires publics ou privés. 


\title{
DABCO-promoted diaryl thioether formation by metal- catalyzed coupling of sodium sulfinates and aryl iodides
}

\author{
Yanpeng Liu, ${ }^{a}$ Long Yin Lam, ${ }^{\mathrm{a}}$ Jiqing Ye, ${ }^{\mathrm{a}}$ Nicolas Blanchard, ${ }^{\mathrm{b}}$ and Cong Ma ${ }^{\mathrm{a}, *}$
}

a State Key Laboratory of Chemical Biology and Drug Discovery, Department of Applied Biology and Chemical Technology, The Hong Kong Polytechnic University, Hung Hom, Kowloon, Hong Kong SAR

E-mail: cong.ma@polyu.edu.hk

b Laboratoire d'Innovation Moléculaire et Applications (LIMA), Université de Haute-Alsace, Université de Strasbourg, CNRS, UMR 7042, Mulhouse, 68200, France

\begin{abstract}
A scalable catalytic synthesis method using commodity chemicals for constructing diaryl thioethers directly from sodium arylsulfinates and iodoarenes is reported in this study. In the presence of $\mathrm{CuO}$ or other copper salts such as $\mathrm{Cu}(\mathrm{OAc})_{2}$ as well as palladium catalysts, DABCO demonstrated to be essential to promote this transformation. Various iodoarenes and aryl sulfinates were examined and demonstrated the viability of this method. The mechanistic study showed that radical reactions occurred, while DABCO $N$-oxide radical can be observed by mass spectrometry. A plausible catalytic mechanism involving $\mathrm{DABCO}$ is also discussed, suggesting synergistic reduction of sulfinate by $\mathrm{Cu}(\mathrm{II})$ and $\mathrm{DABCO}$ is the key step of this coupling reaction.
\end{abstract}

Keywords: catalysis; radical reactions; cross-coupling; thioethers; DABCO

Thioethers are one of the important pharmacophores commonly existing in natural products, pharmaceuticals and bioactive compounds (Figure 1) ${ }^{[1]}$ The application of thioethers in organic materials has also been explored. ${ }^{[2]}$ Generally, the preparation of thioethers are widely performed via transition metalcatalyzed cross-coupling reactions between thiols and aryl or alkyl halides. ${ }^{[3],[4],[5]}$ However, the disadvantages of using thiols in large quantities in industry, such as strong and repulsive odors, irritation to skins, permanent organ damage and even death upon long-term exposure, urge chemists to find more convenient or less hazardous methods for thioether formation.

Other methods that do not rely on thiols as reagents have already been explored. However, some reactive starting materials or reagents had to be used. Arylsulfonyl hydrazide had been approved to be an effective sulfenylating reagent in recent years, sulfonyl hydrazides could react with aryl iodides ${ }^{[6]}$ or boronic $\operatorname{acids}^{[7]}$ to form various thioethers. Additionally, arylsulfonyl chloride ${ }^{[8]}$ and sulfenyl chloride ${ }^{[9]}$ were also developed for the synthesis of thioethers via carbon-sulfur cross-coupling reaction, despite these thiol surrogates being unstable or needing special reaction conditions. Finding more general and stable sulfenylating reagents is still a meaningful and important approach.
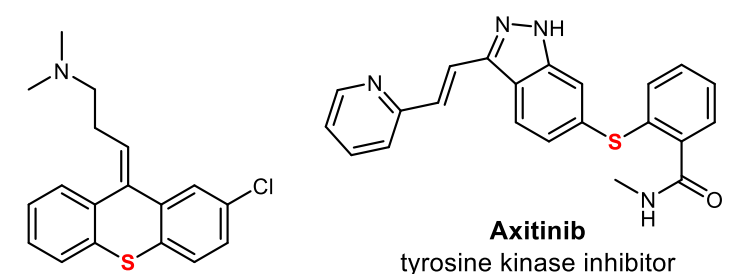

tyrosine kinase inhibitor

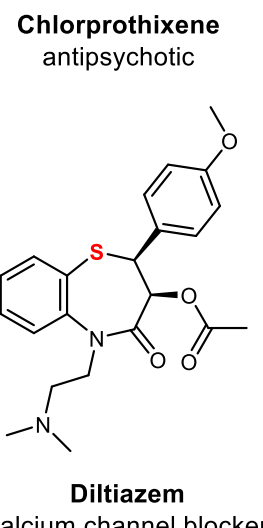<smiles>CC(C)(C)OC(C)(C)OC(C)(C)C</smiles>
antifungal<smiles>O=C(O)c1ccccc1C(=O)c1ccc(Sc2ccc(Cl)c(Cl)c2)c([N+](=O)[O-])c1</smiles>

C3-005

Antimicrobial

Figure 1. Representative thioether-containing drugs and bioactive compounds.

Sodium sulfinate is a stable sulfur-containing reagent without volatility and repulsive odors. Ideally, using sodium sulfinates as sulfur donors to construct thioethers is an attractive aim. Recently, a report demonstrated that aryl sulfones could be synthesized from aryl halides and sodium sulfinates by a coppercatalyzed cross-coupling reaction (Scheme 1a). ${ }^{[10]}$ Moreover, cross coupling reactions for the C3sulfenylation of indoles using sodium sulfinates have also been reported (Scheme 1b). ${ }^{[11]}$ These results encouraged us to develop a novel and more general method to construct thioethers using sodium sulfinates as a convenient type of sulfur surrogates (Scheme 1c). 


\section{Previous works:}

a)<smiles>[R]c1ccc(I)cc1I</smiles><smiles></smiles>

Cul, KOAc

D-glucosamine under air

b)

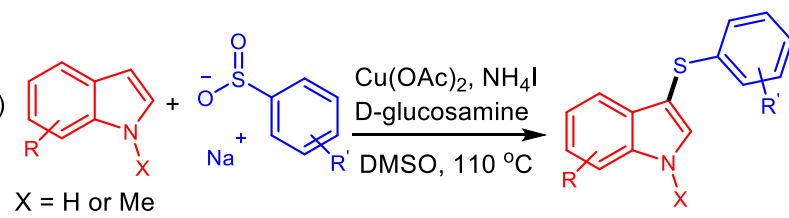

Our work:

c)<smiles>Ic1cc[R]cc1</smiles><smiles></smiles>
$\stackrel{\mathrm{CuO}, \mathrm{DABCO}}{\mathrm{D}-(+) \text {-glucose }}$
$\underset{\mathrm{DMSO}, 120{ }^{\circ} \mathrm{C}}{\longrightarrow}$<smiles>[R]c1ccc(Sc2ccc([R])cc2)cc1</smiles>

Scheme 1. Synthesis of diarylsulfones or 3-arylthioindoles from sodium arylsulfinates.

4-iodotoluene 1a was chosen as a model substrate to avoid the problem of volatility of iodobenzene. ${ }^{[12]}$ Sodium benzenesulfinate $\mathbf{2 a}$ was used as the coupling partner. The original reaction conditions with copper catalysts and D-glucosamine as ligand in DMSO for synthesizing aryl sulfones (Scheme 1a) and indolyl thioethers (Scheme 1b) have been used. However, only trace of thioether coupling product was observed under the conditions of sulfone formation (Table 1, entry 1) and encouragingly, $2 \%$ of thioether 3 could be isolated with copper acetate as the catalyst (Table 1, entry 2). With copper acetate as the catalyst, different acids and bases were screened, and only bases led to the product (Table 1, entries 3-9), in which DMAP started to provide a promising yield of $28 \%$ in the initial screen. We extended the screen to other amine bases and found that DABCO significantly improve the product yield to 55\% (Table 1, entries 5-7). Effectively, Polyzos and co-workers reported a visible light photocatalytic method for thioether formation from aryl iodides and disulfide, and DABCO served as single electron donor in the photocatalytic cycle. ${ }^{[13]}$ Subsequently, DABCO was chosen as the base and various catalysts including commonly used iron catalysts (Table 1, entries 10-12), nickel catalysts (Table 1, entries 13-15) and palladium catalysts (Table 1, entries 16-18) were screened. Iron and nickel catalysts did not lead to favorable results, while palladium catalysts generally conducted to very good yields of thioether product 3 with the highest one is $70 \%$ catalyzed by tris(dibenzylideneacetone) dipalladium $(0)$.

Table 1. Optimization of the reaction conditions (Catalysts and bases) $)^{\text {a) }}$

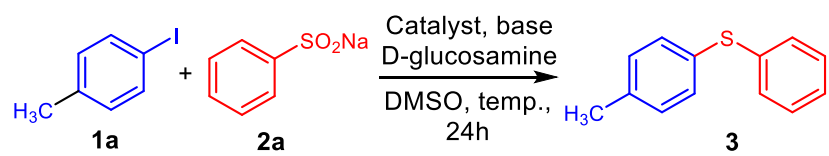

\begin{tabular}{|c|c|c|c|c|}
\hline Entry & Catalyst & Base & $\begin{array}{l}\text { Temp. } \\
\left({ }^{\circ} \mathrm{C}\right)\end{array}$ & $\begin{array}{l}\text { Yield } \\
\left.(\%)^{b}\right)\end{array}$ \\
\hline 1 & $\mathrm{CuI}$ & KOAc & 100 & trace \\
\hline 2 & $\mathrm{Cu}(\mathrm{OAc})_{2}$ & $\mathrm{NH}_{4} \mathrm{I}$ & 110 & 2 \\
\hline 3 & $\mathrm{Cu}(\mathrm{OAc})_{2}$ & $\mathrm{Cs}_{2} \mathrm{CO}_{3}$ & 120 & 3 \\
\hline 4 & $\mathrm{Cu}(\mathrm{OAc})_{2}$ & $\mathrm{Na}_{2} \mathrm{CO}_{3}$ & 120 & 4 \\
\hline 5 & $\mathrm{Cu}(\mathrm{OAc})_{2}$ & $\mathrm{NaHCO}_{3}$ & 120 & 17 \\
\hline 6 & $\mathrm{Cu}(\mathrm{OAc})_{2}$ & DMAP & 120 & 28 \\
\hline 7 & $\mathrm{Cu}(\mathrm{OAc})_{2}$ & $\mathrm{DABCO}$ & 120 & 55 \\
\hline 8 & $\mathrm{Cu}(\mathrm{OAc})_{2}$ & DBU & 120 & 2 \\
\hline 9 & $\mathrm{Cu}(\mathrm{OAc})_{2}$ & DIPEA & 120 & 10 \\
\hline 10 & $\mathrm{FeS}$ & $\mathrm{DABCO}$ & 120 & 2 \\
\hline 11 & $\mathrm{FeCl}_{2}$ & DABCO & 120 & 5 \\
\hline 12 & $\mathrm{Fe}\left(\mathrm{SO}_{3} \mathrm{CF}_{3}\right)_{2}$ & $\mathrm{DABCO}$ & 120 & 5 \\
\hline 13 & $\mathrm{Ni}(\mathrm{dppf}) \mathrm{Cl}_{2}{ }^{\mathrm{c})}$ & DABCO & 120 & 6 \\
\hline 14 & $\mathrm{Ni}(\mathrm{COD}){ }_{2}^{\mathrm{d}}{ }^{2}$ & $\mathrm{DABCO}$ & 120 & 5 \\
\hline 15 & $\mathrm{NiCl}_{2}$ & $\mathrm{DABCO}$ & 120 & 4 \\
\hline 16 & $\left.\mathrm{Pd}_{2}(\mathrm{dba})_{3} \cdot \mathrm{CHCl}_{3}{ }^{\mathrm{e}}\right)$ & $\mathrm{DABCO}$ & 120 & 70 \\
\hline 17 & $\mathrm{PdCl}_{2}\left(\mathrm{PPh}_{3}\right)_{2}$ & $\mathrm{DABCO}$ & 120 & 43 \\
\hline 18 & $\mathrm{PdCl}_{2}(\mathrm{dtbpf})^{\mathrm{f})}$ & $\mathrm{DABCO}$ & 120 & 66 \\
\hline
\end{tabular}

a) Reaction conditions: 4-Iodotoluene $(0.6 \mathrm{mmol})$, sodium benzenesulfinate $(1.8 \mathrm{mmol})$, catalyst $(0.12 \mathrm{mmol})$, ligand (0.12 mmol), DABCO (1.2 mmol), DMSO (2 mL). b) Isolated yield. c) $\mathrm{dppf}=1,1$ ' bis(diphenylphosphino)ferrocene. d) $\mathrm{COD}=1,5-$ cyclooctadiene. e) $\mathrm{dba}=$ dibenzylideneacetone. $\mathrm{f}$ ) $\mathrm{dtbpf}=$ 1,1'-bis(di-tert-butylphosphino)ferrocene.

Consequently, we screened diverse copper catalysts using DABCO as the amine base (Table 2, entries 18 ). The yield of product 3 was further increased to $73 \%$ when $\mathrm{Cu}(\mathrm{OAc})_{2}$ was replaced by $\mathrm{CuO}$ (Table 2 , entry 2). Additionally, diverse ligands were screened when $\mathrm{CuO}$ was used as the catalyst and it seemed that only $N, O$ - and $N, N$-bidentate ligands furnished the thioether product except 1,2-dimethylethylenediamine (DMEDA) (Table 2, entries 9-12). Thioether 3 could be obtained using D-glucose as ligand with a yield of $70 \%$ (Table 2, entry 9), slightly inferior to the reaction conditions using D-Glucosamine (Table 2, entry 2). We were inclined to keep using D-glucose as the ligand for this reaction because of its accessibility and low cost. Finally, we optimized the reaction conditions: the quantity of benzenesulfinate $\mathbf{2 a}$ has been explored (Table 2, entries 13-14). 4 equivalents of $2 \mathbf{a}$ achieved the highest yield of $93 \%$ (Table 2, entry 13 ), while the yield of 3 decreased to $48 \%$ when only 2 equivalents of $\mathbf{2 a}$ were added (Table 2, entry 14). Ligand such as D-glucose was able to significantly increase the reaction yield (Table 2 , entry 15 ), while DABCO base was necessary for this reaction, otherwise the yield of thioether $\mathbf{3}$ dropped dramatically to $13 \%$ (Table 2 , entry 16 ).

Table 2. Optimization of the reaction conditions $(\mathrm{Cu}$ catalysts and ligands) ${ }^{\text {a) }}$

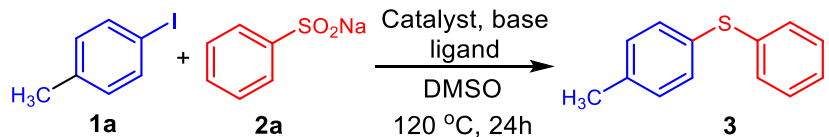




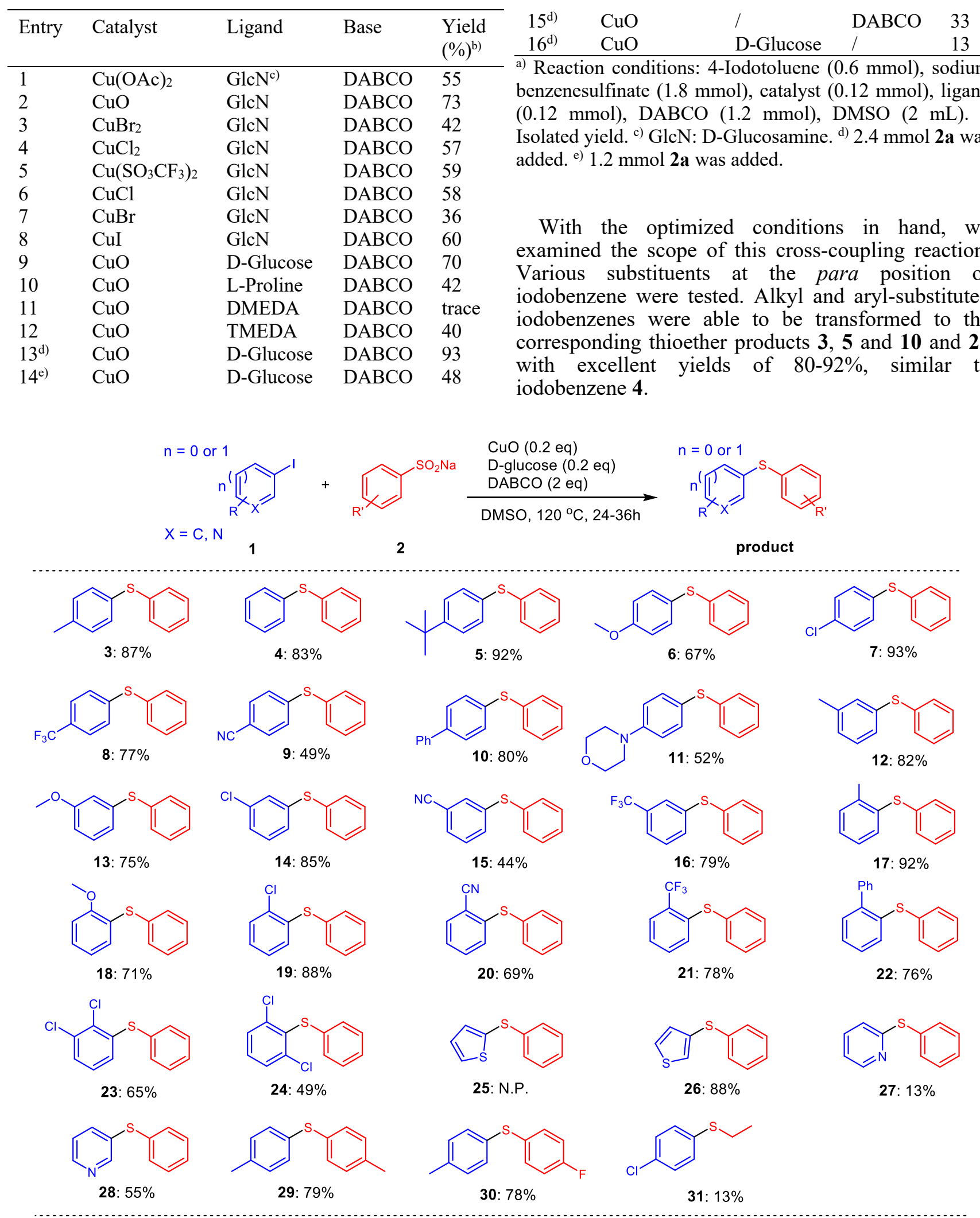

Reaction conditions: 1 (0.6 mmol), $2(2.4 \mathrm{mmol}), \mathrm{CuO}(0.12 \mathrm{mmol}), \mathrm{D}-\mathrm{glucose}(0.12 \mathrm{mmol}), \mathrm{DABCO}(1.2 \mathrm{mmol}), \mathrm{DMSO}(2 \mathrm{~mL}), 24-36 \mathrm{~h}$.

Scheme 2. Synthesis of thioethers.

Electron-donating groups at the para position decreased the yields to $52-67 \%$ (6 and 11 ), while some electron-withdrawing groups did not demonstrate obvious influence on the reactivity to provide the respective yields of $77 \%$ and $93 \%$ from the reactions of 4-Cl and $4-\mathrm{CF}_{3}$ benzene ( 7 and 8 ), except $4-\mathrm{CN}$ substituted iodobenzene, which was obtained with a yield of $49 \%(9)$. Substituents at the ortho $(\mathbf{1 2}-\mathbf{1 6})$ or meta position $(\mathbf{1 7}-\mathbf{2 2})$ of iodobenzene demonstrated a similar trend on the reactivity-substituents 
relationship as at the para position. The best results were obtained with 2-Me iodobenzene (17, 92\% yield) and $2-\mathrm{Cl}$ benzene (19, 88\% yield).

Polysubstituted iodobenzenes were also competent partners in this transformation. 2,3-Di-Cl iodobenzene led to a slightly inferior yield of the desired diaryl thioether $(\mathbf{2 3}, 65 \%)$, while 2,6-di-Cl iodobenzene significantly affected the yield of the product to $49 \%$, probably due to steric hindrance (24). Heteroaryl compounds were also tested. 3-Iodothiophene and 3iodopyridine were transformed to the corresponding products with good to moderate yields $(\mathbf{2 6}, 88 \%$ and $28,55 \%$ ), while an iodine atom at the C2-position of heteroaromatic rings drastically diminished the yields (25 and 27). Finally, diverse benzenesulfinates were examined. Both 4-Me or 4-F benzenesulfinates could be converted to the thioether products in $\sim 80 \%$ yields (29 and 30). Additionally, an attempt using sodium ethanesulfinate demonstrated that this coupling reaction for aryl alkyl thioethers could be performed (31) although with a lower yield.

1)

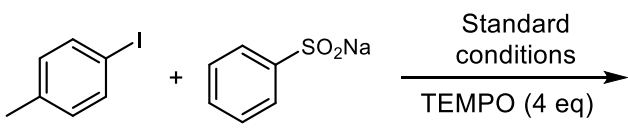<smiles>Cc1ccc(Sc2ccccc2)cc1</smiles>

3: $2 \%$

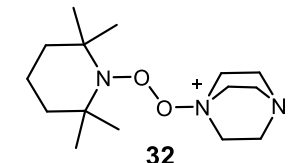

2)

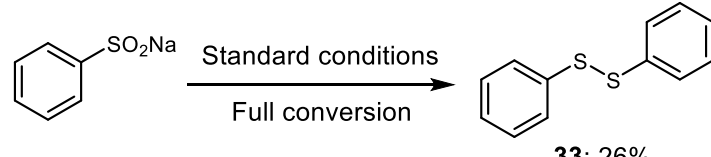

3)

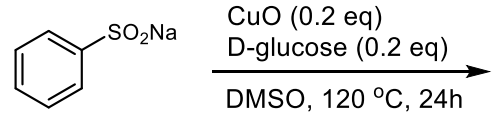

33: $14 \%$

4)

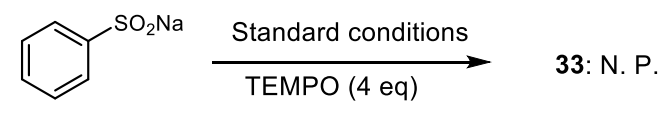

5)
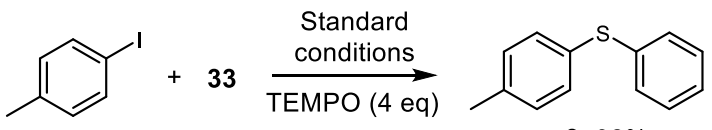

3: $92 \%$

Scheme 3. Control experiments.

In order to support a plausible mechanism of this reaction, a series of control experiments were conducted. When 4 equivalents of TEMPO as the radical trapping reagent were added to the standard reaction conditions, the yield of thioether $\mathbf{3}$ decreased

dramatically to $2 \%$. The result suggested that a radical reaction might mechanistically occurred. The reaction mixture was further examined using mass spectrometry (Scheme 3, entry 1 and Figure S1), and peroxide 32 was detected suggesting DABCO $N$-oxide radical 37 might be involved in the reaction.NEW REF [14]

14: For a related peroxide suggested by ESI-MS, see: J.-H. Xu, W.-B. Wu, J. Wu, Org. Lett. 2019, 21, 5321-5325.

When sodium benzenesulfinate was treated with standard reaction system, disulfide $\mathbf{3 3}$ was isolated with only a yield of $26 \%$ even the conversion was complete (Scheme 3, entry 2), suggesting that disulfide intermediate formation may not be the major mechanism of this reaction.

When DABCO was absent from the reaction, the yield of disulfide 33 further decreased to $14 \%$ (Scheme 3 , entry 3 ), indicating DABCO plays an important role for disulfide formation. When 4 equivalents of TEMPO were added into the standard reaction conditions, no disulfide $\mathbf{3 3}$ was detected (Scheme 3, entry 4). In summary, the results of these three reactions demonstrated that $\mathbf{3 3}$ was formed via the radical pathway, and $\mathrm{DABCO}$ promoted the process. Finally, 4-iodotoluene and $\mathbf{3 3}$ reacted under standard conditions in the presence of 4 equivalents of TEMPO, and $\mathbf{3}$ was formed with $92 \%$ yield (Scheme 3, entry 5). The results suggest that the $\mathrm{CuO}$-catalyzed crosscoupling between 4-iodotoluene 1a and disulfide $\mathbf{3 3}$ follows a canonical mechanism for such $\mathrm{Cu}$-catalyzed C-S bond formation, without the intervention of radical species.

Based on the above results, a plausible mechanism was proposed as shown in Scheme 4. DABCO radical cation 34 can be formed by copper(II) oxidation. ${ }^{[14]}$ The copper(II) oxidation would also transform sodium benzenesulfinate to provide benzenesulfinate radical $\mathbf{3 5}$, which consequently adds to $\mathbf{3 4}$ to form DABCOsulfinate 36. After DABCO $N$-oxide radical 37 leaves, ${ }^{[15]}$ the reduced sulfinyl radical $\mathbf{3 8}$ reacts again with 34 furnishes DABCO-sulfanolate 39. By oxidation of copper(I), thiolate $\mathbf{4 0}$ is obtained and undergo a coupling reaction with 4-iodotoluene to provide the final diaryl thioether product 3 . In the presence of thiolate $\mathbf{4 0}$, the formation of disulfide 33 can be formed spontaneously as an intermediate (Scheme 3, entry 2), 33 could continuously react with 4-iodotoluene to give thioether 3 (Scheme 3, entry 5). 


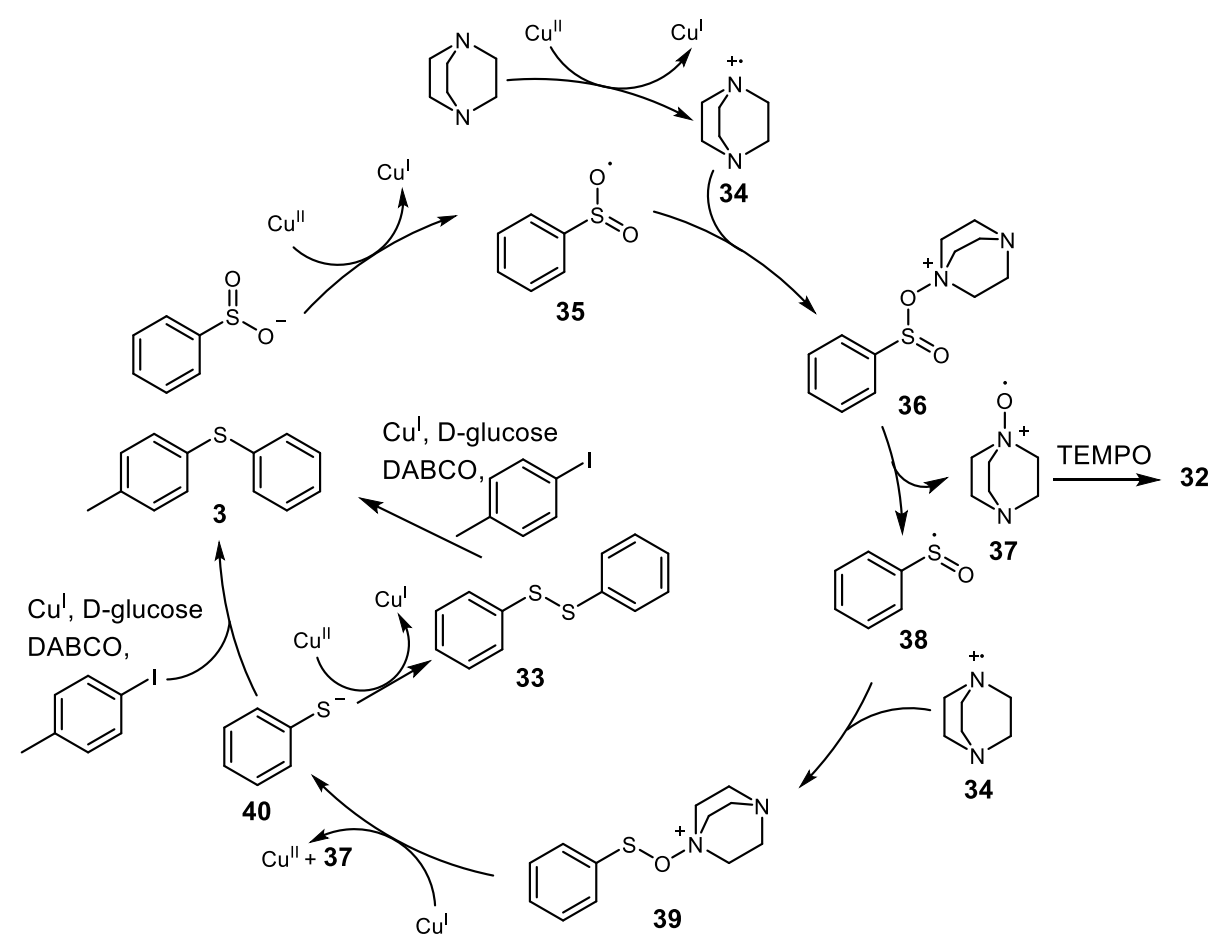

Scheme 4. Proposed mechanism.

A scale up reaction has been set up using $0.52 \mathrm{~g} \mathrm{(2}$ mmol) of 4-t-butyl iodobenzene as the reactant, 4 equivalent of sodium benzenesulfinate was added to the reaction together with copper oxide ( 0.2 eq.), Dglucose (0.2 eq.) and DABCO (2.0 eq.) using DMSO as the solvent. The reaction was stirred at $120^{\circ} \mathrm{C}$ for 24 hours to provide the desired product 5 with a yield of 93\% (Scheme 5).

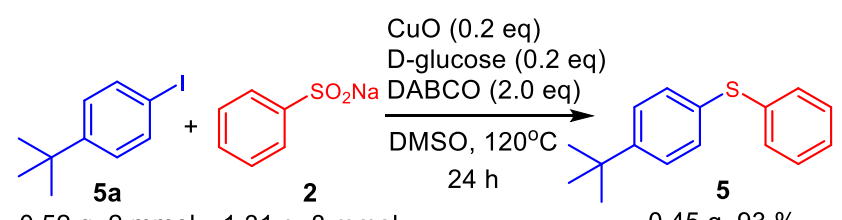

Scheme 5. Scale up reaction of the thioether formation.

In summary, we developed a novel and convenient catalytic method for synthesizing thioethers promoted by DABCO. The thioether can be formed directly from the coupling reaction of sodium arylsulfinate and iodoarene. The reaction scope demonstrated the potential for synthesizing diverse diaryl thioethers and even aryl alkyl ethers, and no highly reactive reducing agent is needed.

The mechanism study suggested a radical pathway by forming a DABCO $N$-oxide radical species from affordable sodium sulfinates rather than commonly used thiols or disulfides. The potential application of our method can be expected.

\section{Experimental Section}

To a stirred solution of sodium sulfinate $2(1.31 \mathrm{~g}, 8.0 \mathrm{mmol})$, $\mathrm{CuO}(31.8 \mathrm{mg}, 0.4 \mathrm{mmol})$, D-glucose $(72.1 \mathrm{mg}, 0.4 \mathrm{mmol})$ and DABCO $(0.45 \mathrm{~g}, 4.0 \mathrm{mmol})$ in DMSO $(10 \mathrm{~mL})$ in sealed tube, was dropwise added 1-(t-butyl)-4-iodobenzene 5a $(0.52 \mathrm{~g}, 2.0 \mathrm{mmol})$. The solution was heated at $120^{\circ} \mathrm{C}$ for 24 hours and monitored by thin layer chromatography. The reaction mixture was cooled to room temperature and added ethyl acetate $(10 \mathrm{~mL})$ to dilute, then the resulting mixture was filtered through diatomite and washed using ethyl acetate $(5 \mathrm{~mL})$ for three times. The filtrate was diluted with water $(20 \mathrm{~mL})$, isolating and collecting the organic layer, and the inorganic layer was extracted with ethyl acetate (5 $\mathrm{mL}$ ) for another two times. The combined organic layer was washed with brine, dried over anhydrous $\mathrm{Na}_{2} \mathrm{SO}_{4}$ and concentrated under reduced pressure. Purification by column chromatography on silica gel (pure hexane) provided $5(0.45 \mathrm{~g})$ as a colorless oil.

\section{Acknowledgements}

We thank the funding support from the Research Grants Council of the Hong Kong Special Administrative Region, China (PolyU 251000/17M and 151000/19M), Hong Kong Polytechnic University internal grants (G-YBYY, 1-ZVPS and large equipment fund) and State Key Laboratory of Chemical Biology and Drug Discovery. We thank Esther Nga Wun Chang for technical assistance. 


\section{References}

[1] a) E. A. Ilardi, E. Vitaku, J. T. Njardarson, J. Med. Chem. 2014, 57, 2832-2842; b) J. Ye, A. J. Chu, L. Lin, X. Yang, C. Ma, Molecules 2019, 24, 2902.

[2] D. A. Boyd, Angew. Chem. Int. Ed. Engl. 2016, 55, 15486-15502.

[3] a) A. Tlili, M. Taillefer in Copper - Mediated Cross Coupling Reactions, (Eds.: E. Gwilherm, N. Blanchard), John Wiley \& Sons, Inc., Hoboken, New Jersey, 2013, pp. 41-91; b) C. G. Bates, R. K. Gujadhur, D. Venkataraman, Org. Lett. 2002, 4, 2803-2806; c) M. Carril, R. SanMartin, E. Dominguez, I. Tellitu, Chem. Eur. J. 2007, 13, 5100-5105; d) A. Correa, M. Carril, C. Bolm, Angew. Chem. Int. Ed. Engl. 2008, 47, 2880-2883; e) K. S. Sindhu, T. G. Abi, G. Mathai, G. Anilkumar, Polyhedron 2019, 158, 270-276; f) A. P. Thankachan, K. S. Sindhu, K. K. Krishnan, G. Anilkumar, RSC Adv. 2015, 5, 32675-32678; g) G. Evano, N. Blanchard, M. Toumi, Chem. Rev. 2008, 108, 3054-3131.

[4] a) C. W. Chen, Y. L. Chen, D. M. Reddy, K. Du, C. E. Li, B. H. Shih, Y. J. Xue, C. F. Lee, Chem. Eur. J. 2017, 23, 10087-10091; b) M. Jiang, H. Li, H. Yang, H. Fu, Angew. Chem. Int. Ed. Engl. 2017, 56, 874-879; c) K. D. Jones, D. J. Power, D. Bierer, K. M. Gericke, S. G. Stewart, Org. Lett. 2018, 20, 208-211.

[5] a) R. B. N. Baig, B. R. Vaddula, M. N. Nadagouda, R. S. Varma, Green Chem. 2015, 17, 1243-1248; b) E. Guzman-Percastegui, D. J. Hernandez, I. Castillo, Chem. Commun. 2016, 52, 3111-3114.

[6] a) V. Saini, B. Khungar, New J. Chem. 2018, 42, 1279612801; b) N. Singh, R. Singh, D. S. Raghuvanshi, K. N. Singh, Org. Lett. 2013, 15, 5874-5877.

[7] a) R. Singh, B. K. Allam, N. Singh, K. Kumari, S. K. Singh, K. N. Singh, Adv. Synth. Catal. 2015, 357, 11811186; b) T.-T. Wang, F.-L. Yang, S.-K. Tian, Adv. Synth. Catal. 2015, 357, 928-932.

[8] Y. Wang, X. Zhang, H. Liu, H. Chen, D. Huang, Org. Chem. Front. 2017, 4, 31-36.

[9] P. Gogoi, M. Kalita, P. Barman, Synlett 2014, 25, 866870 .

[10] M. Yang, H. Shen, Y. Li, C. Shen, P. Zhang, RSC Adv. 2014, 4, 26295-26300.

[11] a) X. Ge, F. Sun, X. Liu, X. Chen, C. Qian, S. Zhou, New J. Chem. 2017, 41, 13175-13180; b) P. Katrun, S. Hongthong, S. Hlekhlai, M. Pohmakotr, V. Reutrakul, D. Soorukram, T. Jaipetch, C. Kuhakarn, RSC Adv. 2014, 4; c) A. C. Nassoy, P. Raubo, J. P. Harrity, Chem. Commun. 2015, 51, 5914-5916; d) Y.-m. Lin, G.-p. Lu, G.-x. Wang, W.-b. Yi, Adv. Synth. Catal. 2016, 358, 4100-4105; e) F. Xiao, H. Xie, S. Liu, G.-J. Deng, Adv. Synth. Catal. 2014, 356, 364-368; f) Z. Huang, O. Matsubara, S. Jia, E. Tokunaga, N. Shibata, Org. Lett. 2017, 19, 934-937; g) M.-j. Bu, G.-p. Lu, C. Cai, Org. Chem. Front. 2017, 4, 266-270; h) H. Rao, P. Wang, J. Wang, Z. Li, X. Sun, S. Cao, RSC Adv. 2014, 4, 49165-49169.
[12] The present study focuses on the reactivity of aromatic iodides. As noted by a referee, aromatic chlorides and bromides might also be competent partners, at higher temperature.

[13] M. Jouffroy, C. B. Kelly, G. A. Molander, Org. Lett. 2016, 18, 876-879.

[14] a) G. Balakrishnan, T. Keszthelyi, R. Wilbrandt, J. M. Zwier, A. M. Brouwer, W. J. Buma, J. Phys. Chem. A 2000, 104, 1834-1841; b) J. L. Jeffrey, F. R. Petronijevic, D. W. MacMillan, J. Am. Chem. Soc. 2015, 137, 84048407.

[15] J. H. Xu, W. B. Wu, J. Wu, Org. Lett. 2019, 21, 53215325. 
